\title{
Synergistic Social Technology: Designing Systems with 'Needs' that Encourage and Support Social Interaction
}

\author{
Ella Dagan \\ University of California Santa Cruz \\ Santa Cruz, CA, USA \\ ella@ucsc.edu
}

\author{
Katherine Isbister \\ University of California Santa Cruz \\ Santa Cruz, CA, USA \\ katherine.isbister@ucsc.edu
}

\begin{tabular}{|c|c|c|c|}
\hline Core Principles & Synergistic Social Technology (SST) & \multicolumn{2}{|r|}{ Strong Concept Grounding } \\
\hline Systems are designed with 'need(s)' & Terhnolnoy & \multirow{3}{*}{ 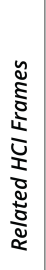 } & \multirow{3}{*}{$\begin{array}{l}\text { - Animism } \\
\text { - Object Oriented Theory } \\
\text { - Interdependent Wearables } \\
\text { - Social Roles } \\
\text { - Vulnerability } \\
\text { - Matters of Care }\end{array}$} \\
\hline $\begin{array}{l}\text { The 'need(s)' encourage people to interact } \\
\text { because they are compelling and essential } \\
\text { for them }\end{array}$ & 'Need(s)' & & \\
\hline $\begin{array}{l}\text { Fulfilling the 'need(s)' of the system results } \\
\text { in positive social implications for the people } \\
\text { who use it }\end{array}$ & Synergy & & \\
\hline $\begin{array}{l}\text { Interactions are designed while thinking } \\
\text { beyond the individual level of interaction }\end{array}$ & Humans & $\tilde{\omega}$ & $\begin{array}{l}\text { - The Robo-Shoe-Flies } \\
\text { - Data Hungry Home (DHH) }\end{array}$ \\
\hline $\begin{array}{l}\text { Building 'synergies' between the real needs } \\
\text { of people and the 'need(s)' of the system }\end{array}$ & Social Implications & 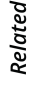 & $\begin{array}{l}\text { - Social Media Platforms } \\
\text { - Lågom }\end{array}$ \\
\hline
\end{tabular}

Figure 1: Synergistic Social Technology (SST) concept grounding: core principles, related theory, and related instances.

\begin{abstract}
In this paper, we propose a strong concept for interaction design: Synergistic Social Technology (SST). This concept describes systems in which technology is designed with its own 'need' for interaction. As a result of responding to these needs, people who use the system may benefit from social interaction with others who use the system. This concept arose through the design, prototyping, and study of a social wearable design that we called Robo-ShoeFlies. We articulate the core principles of the SST concept. We also describe the Research-through-Design process that inspired its development and associated design-focused observations. This work may inspire those in the IxD or HCI communities focused on the design and development of technology intended to support social interaction, particularly in the sense of encouraging collective, mutually-beneficial action.
\end{abstract}

wicensed under a Creative Common

Attribution-NonCommercial-ShareAlike International 4.0 License.

DIS '21, fune 28-fuly 2, 2021, Virtual Event, USA

(c) 2021 Copyright held by the owner/author(s).

ACM ISBN 978-1-4503-8476-6/21/06.

https://doi.org/10.1145/3461778.3462021

\section{CCS CONCEPTS}

- Human-centered computing $\rightarrow$ Collaborative and social computing theory, concepts and paradigms; Interaction design.

\section{KEYWORDS}

strong concept, Research through Design, social wearables, synergistic, social, co-located

\section{ACM Reference Format:}

Ella Dagan and Katherine Isbister. 2021. Synergistic Social Technology: Designing Systems with 'Needs' that Encourage and Support Social Interaction. In Designing Interactive Systems Conference 2021 (DIS '21), fune 28-fuly 2, 2021, Virtual Event, USA. ACM, New York, NY, USA, 14 pages. https://doi.org/10.1145/3461778.3462021

\section{INTRODUCTION}

The core contribution of this paper is proposing Synergistic Social Technology (SST) as a strong concept. Strong concepts are considered intermediate-level knowledge contributions. They "are design elements abstracted beyond particular instances which have the potential to be appropriated by designers and researchers to extend their repertoires and enable new particulars instantiations" [29]. In addition, we present an exploratory social wearable system, which inspired the development of SST, along with design-focused observations based on a preliminary study of the system. The concept and 
our observations may be useful for other designers and researchers interested in encouraging social interaction.

The motivation for developing SST as a strong concept was our research team's ongoing interest in sharpening design practice concerning opportunities to foster a sense of community and connection among people who use our interactive technology. We had the insight during the Research-through- Design (RtD) [25] project described in this paper, that we could position the technology as in need of care. Not just care at an individual level, but at a collective level across devices and multiple people. And that this care could, in turn, help to foster connection and community among people who engaged with the technology.

We are particularly interested in developing technologies that augment co-located socializing (in the same physical spaces). That is why the exploratory wearable system described in this paper focuses on this use case. We agree with Olsson et al. who emphasize that there is a need to not only enable co-located social interaction, but also design technology that actively and deliberately attempts to improve its quality, value, and extent [55]. Tromp et al. argue that "although designers can never fully predict the social implications of their design, and although the political significance of artifacts changes over time," [72] they should consider the social implications of their designs [72]. We strongly agree with this point of view and believe it is true that "every technology can deliberately or inadvertently impact psychological wellbeing” [57]. Therefore we find it very important to address the neglect of co-located social support head-on.

Motivated by these aims, we set out to design a system that would not just enable, but actively support and encourage co-located social interaction. The rest of the paper proceeds as follows: 1) We propose the synergistic social technology as a strong concept, grounding it horizontally in the context of related HCI theory [29], 2) We describe the system and RtD process that inspired the articulation of the concept, then 3) We discuss design-focused findings from studying the system and how the SST concept developed. Finally, 4) We discuss SST in regards to other systems (vertical grounding [29]) and future possible applications. We conclude with general observations about the generative possibilities of the strong concept for others in the design community at large.

\section{ARTICULATING SYNERGISTIC SOCIAL TECHNOLOGY (SST) AS A STRONG CONCEPT}

Strong concepts can abstract design elements beyond particular instances. This abstraction lets designers and researchers appropriate them in their practice: extending their repertoires and enabling new concept instantiations [29]. In this section, we explain the Synergistic Social Technology (SST) concept and ground it in related HCI theory.

\subsection{What is SST?}

By Synergistic Social Technology (SST) we mean that the technologies are designed to have 'needs' that motivate people to engage. As a direct result of responding to these needs, people find themselves interacting with others synchronously and collaboratively. So, by synergistic, we mean that the technology benefits from getting its 'need' met by the people's engaging with it, while people benefit from being 'encouraged' to engage in social interaction.

Our concept suggests that designers consciously design compelling and essential interactions as part of systems. These interactions should create synergies between meeting the 'need(s)' of the system and social interaction among the people who use it. Ideally, these interactions also aid people in conceiving of themselves as part of a community of care, thinking beyond the individual level of interaction.

We want to note that by 'need(s)' we do not necessarily mean the technology's technical requirements (such as a need for electric power). We are casting needs in an animistic sense: the designers craft a framing story for the technology that assigns 'need(s)' that must be met in socially beneficial ways by the people who use the system. One can imagine situations in which the technical requirements of a system might incidentally drive social interaction. For example, electric vehicles need charging. When charging a vehicle in a public setting (e.g., a parking lot), people may encounter others and consequently interact with them. It may also lead to people interacting with others by forming social clubs around improving, or even just showing off their vehicles to one another, or creating services for repair and maintenance. However, these possible interactions between people are not required by the design of the technology and are thus auxiliary effects.

The SST concept draws upon a range of HCI theoretical frames while adding a collective-minded, animistic perspective. It focuses on systems of humans and technology working together. Fig. 1 highlights the proposed SST concept, its design implications, and the related HCI theory and design instances.

We consider the core principles of SST to be:

- Systems designed with 'need(s)': by crafted a framing story that casts them in an animistic sense (e.g., 'needing' to connect devices after several hours of actively using them because the devices'rely on each other to survive').

- The 'need(s)' encourage the people who use the system to interact because they are compelling and essential for them as humans (e.g., taking a break from the screen).

- When people fulfill the system's 'need(s)' they experience positive social implications (e.g., people meet to exchange access information in order to connect their devices).

- The interactions are designed to work beyond the individual level of use - they are designed to foster a sense of community (e.g. people rely on each other for the exchange of information, they cannot complete a task on their own).

- Building 'synergies' between real human needs and the 'need(s)' of the system.

\subsection{Related HCI Theory}

An important aspect of articulating strong concepts is situating them in the context of related HCI theory (what Höök and Lowgren term "horizontal grounding" [29]). Here we position our strong concept in the HCI theory landscape:

Matters of Care. At a general level, Puig de la Bellacasa proposed the notion of "Matters of Care", saying "Can we contribute, by carefully staging how things hold together, to more sustainable caring relationalities and life conditions in an aching world?” This 
call to action was meant to inspire others to create "what is needed to generate more caring relationships" [16].

Interdependent Wearables. A strong concept in the HCI literature closely related to our SST concept is that of interdependent wearables [33]. This concept suggests that incorporating interdependencies between wearers in interaction design may lead to pro-social behavior, facilitating collaboration, coordination, and mutual attention [33]. Our strong concept extends this by integrating animistic qualities that help encode the technology's 'need' for interaction into the backstory of the design.

Animism. In [74], Van Ellen et al. suggest that "Using animism as a metaphor, designers can create simple yet powerful mental models that people can use for their digital devices, environments, and systems. People are expert at and comfortable understanding things that are alive, and this provides an efficient and expressive shorthand for the designer to communicate the system's approach, affordances, and state" [74]. Also, they write: "Animism, as distinct from anthropomorphism, however, offers a way of separating out issues of ascribed intelligence from ascribed intentionality or inner-life [... which] directly engages with the myth-making narrative tendencies of the human mind" [74]. Their suggested use of animism as a metaphor articulates the benefit of encoding a backstory into the design. It may help flesh out the "intentionality." In our SST concept we suggest drawing from animism to create a sense of relationship to the technology. This relationship could allow for scripting the design with 'needs.' These needs could then be met by people collaboratively, encouraging them to engage with one another.

Object Orientated Ontology. Another related theory is 'Object Orientated Ontology' (OOO) [28], a branch in contemporary philosophy of technology and a strand of 'speculative realism' [27]. Lindley, Coulton, and Cooper explain OOO as "a model for being where no object is more significant than any other object," which includes humans. Objects (or things), therefore, are "not merely defined through human use but through any use, including object to object situations" [43]. Wakkary et al. suggest that "[t]hings can be seen as non-human technological entities and artifact entities often bound together that are conditioned by humans and in turn shape what it means to be human" [77].

To explore the gap between things and people, they designed and fabricated six sets of networked ceramic bowls and cups (named the Morse Things) to help them investigate IoT from a thing-centered perspective and human-technology relations. These artifacts were then given to domain expert as participants to live with them for several weeks [77]. One of their main findings was the search for humanness: "Participants projected human emotions and experiences on the Morse Things" [77]. The findings from this study suggest that even if the design or artifact is introduced as a pragmatic "thing," such a set of bowls and cups, people still tend to associate animistic qualities to it, and initiate myth-making.

They also found that "[w] hile the Morse Things were often approached from a human centered perspective, on many occasions a more thing-oriented projection came through" [77]. This result suggests people can, at times, consider designs from a "thing-centeredness" perspective as well. We see the Synergistic Social Technology concept positioned somewhere between $\mathrm{OOO}$ and a traditional understanding of technologies as in a separate ontological category from the people using it. We propose a synergistic relationship between "things" and humans while focusing our interest on social outcomes for humans as they use the system [72].

Social Roles. Others in the HCI community propose using framing concepts from social psychology, such as social roles, to help set expectations for interaction with technology. This perspective can leverage human to human expectations "in interaction with others without having to negotiate everything about how each person will act, and often, without even having to get to know one another very well" [31].

Paradigms of Human-Robot Relationship. In Human-RobotInteraction (HRI) research there are two common paradigms of human-robot relationship: (i) the caretaker paradigm: "the role of the human is to identify and respond to the robot's emotional and social 'needs'. The human needs to keep the robot 'happy' which implies showing behaviors towards the robot characteristic of behavior towards infants or baby animals" [15] as well as (ii) the assistant/companion paradigm: which "considers robots as caretakers or assistants of humans" [15]. We position the Synergistic Social Technology concept in this larger tradition of setting up legible relationships between technology and people while avoiding the explicit anthropomorphism of these other theoretical frames. SST should be considered more animistic than anthropomorphic to allow for a broader range of potential synergies and relations.

Vulnerability. SST also relates to the experiential design quality of vulnerability [12]. From an emotional and social angle, there are benefits to disclosing and sharing vulnerabilities with others when appropriate [8]. Vulnerability, when included in technology design strategically and thoughtfully, may impact the sense of social empowerment and connection [12]. SST suggests incorporating artificial need(s) in the design of the technology. These need(s) make the technology somewhat vulnerable as it relies on humans to care for it (beyond regular maintenance such as battery charging or rebooting). Also, SST suggests that the humans who use the technology would only be able to do so if they collaborate with others, and that puts them in the vulnerable position of needing to find other people, to care for the technology together.

\section{THE DESIGN THAT INSPIRED THE SYNERGISTIC SOCIAL TECHNOLOGY CONCEPT DEVELOPMENT}

The Synergistic Social Technology (SST) concept emerged from the development of a particular prototype. The process of designing, developing, and studying this prototype led us to the SST concept.

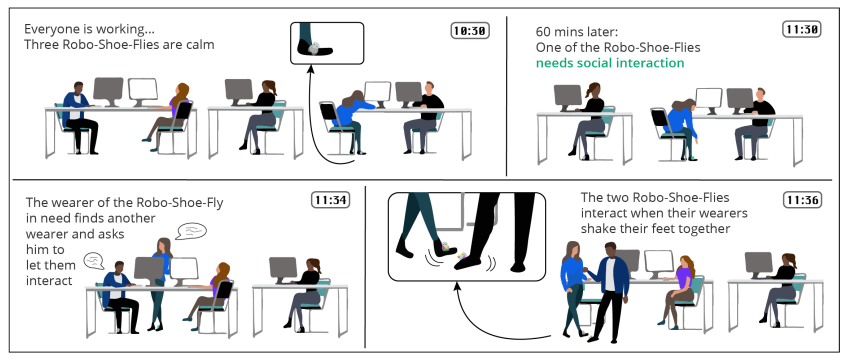

Figure 2: Illustration of the Robo-Shoe-Flies in office use. 
Here we present the Robo-Shoe-Flies design as a case study to show how we came to articulate the concept based on our RtD process. We briefly introduce the system, contextualize it with related work, and then describe the design process and its interactive and technical features. Finally, we include details about studying the design with people, and our findings.

\subsection{Introducing the Robo-Shoe-Flies}

Here, we briefly present the design prototypes of the Robo-ShoeFlies and how they function (see Figs. 2, 5). With this design, we wanted to explore ways to encourage people to socialize with colocated others. We were also looking for possible motivations for engagement and positive activities that could facilitate some aspects of wellbeing. To do so, we played with the idea that wearables would resemble a kind of creature that could "dwell" on the body.

Therefore, we framed our social wearables as a community of on-body 'robotic' companions who 'need' movement and social interaction with other creatures of their species occasionally. The creatures provide sound and visual feedback to signal to their wearers their 'needs.' When wearers receive this feedback, they should find another person (who also wears a creature) and let the creatures interact by coordinating movement together- by facing the creatures towards one another and shaking their right feet. We imagined people would wear the creatures in an office or a desk job-like setting, where people usually spend their time sitting in front of a computer. We speculated that having an external reason to move around and socialize might benefit people and serve as a short 'brain break' [11].

\subsection{Work Related to the Robo-Shoe-Flies Concept Development}

Related work that influenced, motivated, and guided our design process covers a range of topics.

3.2.1 The value in co-located interaction. The value sensitive design approach to technology design accounts for human values "in a principled and comprehensive manner throughout the design process" [23]. HCI researchers have recently proposed to the scholarly community to "steer future technological developments toward putting attention on the experiential space between people, deploying computation toward augmenting physical copresence and collective action" [32], and articulated the need for better technologies that work to enhance co-located social interaction [55]. The impact on co-located interaction is often neglected in commercial wearables design [49]. However, researchers have begun to identify areas of value to consider for those who work in the design space of social wearables [13], wearable technology that augments in-person social interactions [49]. In our work, we wanted to explore wearable design that caters to such interactions.

3.2.2 Design motivation: facilitating positive activities. Practicing positive activities may boost wellbeing [48]. Activities such as taking care of body and mind, committing to one's goals, and investing in social connection were identified as interventions "linked to lasting increases in well-being" [78]. Research suggest that workplace occupational sitting is associated with negative health outcomes [54, 70]. Yet there is a growing trend of Millennials not even taking lunch breaks away from their desk [52] (interestingly, commercially available wearable devices are insufficient for reducing sitting time [68]). Research suggests that social and physical play has positive effects such as increased engagement and positive emotions [65], and playful interactions can bring joy "to otherwise unstimulating moments" [5]. Researchers have also shown that people may also benefit from taking breaks from work [66], and particularly breaks that include movement [69] and social breaks [76] for knowledge workers [19].

3.2.3 Exploring foot-based interaction. In our design process we engaged in embodied sketching, a method that supports the ideation phase rather than evaluation, and allows for "the inclusion of bodily experiences early in the design process", to "spur creativity by harnessing play and playfulness" [50] (it is a form of embodied storming, that lets us "take advantage of the collective's unique ability to distribute cognitive facility in the tangible, physical performance of activity" [62]). During this process, we experimented by moving our feet to interact with each other. We enjoyed doing so and realized that moving one's feet can engage the body in more holistic movement (rather than just waving one's hand, for example). We chose to include this currently under-explored body interaction in wearable design in our system. Research in HCI on foot-based interaction [75] mostly focuses on foot movement as an input modality to interact with screens (e.g., $[20,47,61])$, to interact with virtual and mixed environments (e.g.,[53, 80]), and by using tangibles (e.g. [63]). There are also a few commercial wearable shoe accessories that function as game controllers to support screen-based interaction (e.g., [1]) or virtual-reality (e.g., [2]). Commercial foot-based wearables have mostly focused on biometric measures for health, performance and training (e.g., $[18,60])$, or tracking GPS signals for safety measures (e.g. [17]).

3.2.4 Designing technology with creature-like attributes. When tangible technology design (such as a wearable) is presented to users with creature-like attributes, it becomes useful to think of it in the context of human-robot interaction (based on insights from [35]). Researchers surveyed users to learn about their expectations of on-body companion robots. They identified a few potential applications that include: entertainment, companionship for lonely people, a partner to play games with, to help motivate the user to exercise, or to keep people company when they travel, to name a few [34]. Currently, research on social robots or smart pets/robotic companions has mostly explored individual companions whose socialization is focused on human-robot interactions [7, 15, 22, 46, 58]. Also, their socialization has been explored in regards to supporting specific populations (e.g., older adults [38], or adolescents with Myalgic Encephalomyelitis (a condition that reduces their normal functioning, including the ability to socialize) [10]. However, there are still critical knowledge gaps for designing social robots. For example, in understanding the mechanisms that encourage communication between humans and robots. Including how behavior between them occurs and how humans interact with each other around them [7].

3.2.5 Related Technology Designs. Here we describe related researchbased and commercial products that share some aspects with the design of our system. A few projects explore wearables with creaturelike features. For example, the robotic arm cuff named Ref [37] is 
a design concept of a wearable wrist-worn creature that responds to the wearer's pulse measures by changing its shape (twisting, curling). Its purpose is to make the wearer more aware of their emotional state and support their relaxation and wellbeing. Hooze [79] is a fashion accessory with playful and zoomorphic qualities, which entices people to touch it. Other related designs aim to encourage physical activity. For example, Nintendo's Pocket Pikachu pedometer [9] has a virtual character that responds to step count by becoming happier as it increases, and encourages physical activity by learning new tricks. Another design, the Pediluma [41], is a wearable shoe accessory that aims to encourage physical activity by tracking and using light to visualize the wearers' movement. There are also many examples of commercial wearable wrist-worn fitness trackers that attempt to support people to be generally more active (e.g., Fitbit [4] and Apple Watch [6] to name a few).

In our design, we also wanted to create a system that encourages people to take breaks from their work. From a commercial perspective, many apps try to encourage and support people to take breaks away from their screens [21]. From a design research standpoint, two projects are especially inspiring. The Breakbot is a companion robot design concept that sits on workers' desks to remind them to socialize and take breaks [59], and the Break-Time Barometer focuses on the social benefit of taking breaks with other people in the workplace. It uses "an ambient persuasion approach in order to encourage people to join existing breaks" [36].

\subsection{Design Process}

Our interest in enhancing co-located social interaction guided our inquiry. We chose to explore the design space of social wearables (namely, wearable technology designed to augment in-person social interaction [49]). In particular, we were interested in the underexplored area of wearables that proactively intervene in the social situation [13]. Designs that fit into this category create a clear and actionable call for interaction (e.g., task-oriented interaction, a collaborative creation) and may utilize more than one device, and also may affect sociospatial proxemics [13].

We began the design process by using the PLEX cards [45], randomly selecting a few cards from the deck. PLEX Cards are considered a valuable source for brainstorming inspiration when designing for playfulness. Our goal was not strictly to design playful interactions, but engaging with these cards helped us begin brainstorming playfully and loosely and keep an open mind. We planned to prototype our design with the Adafruit Circuit Playground Express (CPX) [30], as we had multiple boards available to us in our lab, and we appreciated its prototyping flexibility (in terms of development and hardware). So we engaged in embodied sketching [50] by taking turns to decide upon on-body locations. We taped the CPX boards to the suggested bodily location and began to move around in the space and interact with each other playfully (see Fig. 3)

We were examining the somatic experience of wearing the boards in these on-body locations and exploring opportunities for new interaction among us (a similar approach to that advocated by [71]). Our inquiry was also guided by questions from the design framework for social wearables [13]: What is being sensed? What means or gestures are required? Does activating the device

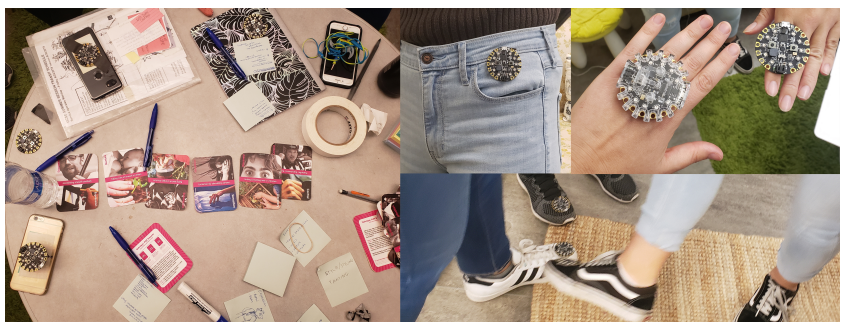

Figure 3: Photos from our embodied sketching design ideation session with the cards.

happen automatically or require people's intentional input? Is the output/feedback noticeable? By the wearer? By others? Through which means? How many devices are there? What is the interplay between them? What degree of focused attention is required from the wearer and others? In what social environment does interaction occur? What is the best on-body location for the wearable to bring people together?.

As we were trying varying body locations for the CPX, we challenged ourselves to expand away from prevalent wearable technology on-body location sites and explore new possibilities. In particular, we enjoyed the interaction between us when the CPXs were taped to our shoes. We started playing with this on-body location - we began shaking our feet at each other. We then found an inspiring viral video [26] of people doing a foot shaking dance! We thought it could be an interesting interaction between two people. We imagined that if people coordinate a 'foot shake' they would spend some time with each other. And while they do so, they would probably be looking down at their shoes, so they will not need to directly look at each others' faces. We thought this might eliminate some tension for people, especially if they were interacting with people they did not know very well.

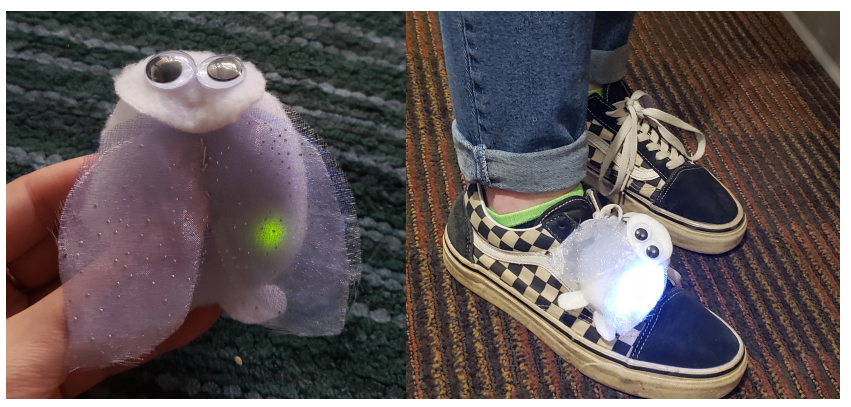

Figure 4: Left - The Robo-Shoe-Flies cover; Right - RoboShoe-Fly dwells on the shoe.

In addition to our initial goal (of enhancing and supporting people to interact with other co-located people), our embodied design brainstorming session resulted in thinking also about taking breaks from work, getting up from sitting for long hours, moving around, and caring for another person or device. Thus, our assumptions about activities that may positively affect aspects of one's wellbeing drove some of our design decisions. 
In our process, we found a social wearable that was presented to participants with a fictional backstory [14] inspiring. We then began to develop our design backstory by thinking of our wearables as 'creatures' with 'needs.' To inspire the look of our creatures four of us individually created moodboards on Pinterest (which we later combined into one board). We noticed we gravitated towards fuzzy and cute bug-like animals in our moodboards. In our design, we were constrained by the CPX board shape and size and by the additional lithium battery, all of which had to fit in an enclosure. These considerations guided the tangible aspects of our wearable design prototype.

After making a few sketches of creatures, we settled on one that worked well with the CPX's visual feedback (10 built-in LEDs arranged in a ring). We created seven multiple soft covers (see Fig. 7-Right): we gave the creatures a 'face' with googly eyes, two small feet, and attached three layers of soft wings for added texture and dimensionality in the design aesthetic (see Fig. 4-Right, 7). The enclosure had an extended piece on its back for connecting it to the wearers' shoelaces (by tying and wrapping it around, see Fig. 6).

\subsection{Interaction and Technical Features}

We used the CPX board's built-in LED ring for visual feedback. We also used its speaker, accelerometer, internal clock, and infrared (IR) sensing capabilities to create interaction among the creatures and their wearers. We used IR and acceleration sensing to register when the interaction between creatures happened; when a creature senses that it shakes (through changes in accelerometer data) it sends IR signals. Then, if another creature is nearby, it can receive the signals.

We were intrigued by the timer interaction modality in [12], which uses a timer to trigger signals of change in the wearable's state. This interaction strategy is similar to other types of technologydirected 'notifications.' We designed our creatures to 'need' interaction occasionally. Therefore we programmed the CPX to utilize its internal clock as a timer to turn on the first 'nudge' after 60 minutes, and then again between 30 to 100 minutes intervals, depending on its previous interactions (adjusted from [56]). The purpose of the first nudge is to let the wearer (and co-located others) know the creature 'needs' the interaction. Then, within 10 minutes of this nudge, if the device does not register the required interaction (by receiving IR signal from another device) it nudges again (and changes the color of the flashing light display from green to red).

The wearers are supposed to coordinate shaking their right feet and direct the creatures to face each other (to send and receive IR signals). If the wearer has found another wearer and their device has sensed the IR signal, then the creatures will flash scattered rainbow light animation and play a 'happy' tune to signal to their wearers that they are content with the interaction. Wearers could also find each other and let their creatures interact by shaking feet even without a nudge. This interaction would also satisfy their creatures' 'need' to interact and reset their timers to delay subsequent nudges.

We iterated the initial prototypes several times, exploring different interaction modalities, timings, and feedback among ourselves. Lab members and guests tested variations of the prototype during in-lab group discussions. Here we share a few anecdotes from our iterative process. We thought it could be interesting to shake legs

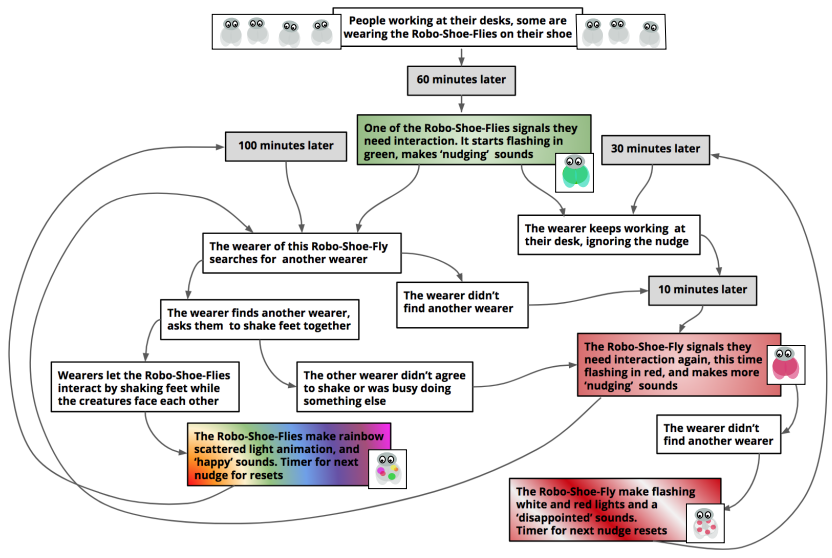

Figure 5: Robo-Shoe-Flies interaction flow diagram.

with others (to resemble the type of unique fist-bumps/handshakes people playfully make up) so our design included complex foot gestures initially. We had a sequence of foot gestures that required a lot of coordination (such as shaking legs back and forth and sideways in very particular ways). We iterated on this idea and worked towards figuring out ways to detect these gestures with the CPX.

Then we took our early prototypes (the CPX boards with the first iteration of the code encased in our enclosure) to internal playtesting with four people who were not from our lab. We instructed them in how to use the wearables and observed their interaction, and later conducted an informal group interview with them. We then realized that unique complex foot coordination is hard to explain and hard to learn. We also realized it was unnecessary for our use scenario, and decided to remove it in the next code iteration.

Another thing we noticed was that there might be a gendered difference regarding how people shake their legs. While we were a group of cis-gender women developing the prototypes, our internal play-testers were all seemingly cis-gender men. It was clear that there was a big difference between how they shook their legs (vigorously) and how we shook our legs (gently). So, we adjusted the thresholds for the shaking detection, essentially making it so there was no more need for unique complex foot coordination besides detecting there was some sort of shake (whether vigorous, gentle, or otherwise), and IR was detected.

We also iterated on the time intervals and the length of time that foot shaking was required. We thought people should shake for several seconds in a coordinated manner to provide a structure for their interaction. We thought that defining a time-frame for the time they spent with each other would be helpful. However, as we continuously tested the design among ourselves, we realized it is too difficult to define the proper amount of time that feels pleasant and acceptable to shake feet. Therefore, in the latest prototype, we removed the constraint of a strict amount of time for shaking to be detected. The devices need only to detect that shaking happened to send IR signals. We also programmed in an added feature that would let us follow up on how many times the creature had satisfactory interactions. By pressing a button, we can display the number (1-5) of green LEDs on the right side of the CPX ring, and the times it nudged the wearer to interact but did not register a satisfying 


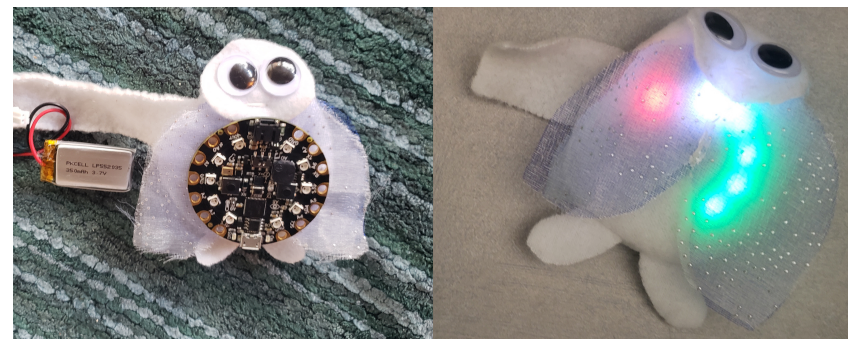

Figure 6: Left - the CPX and the battery can fit inside the Robo-Shoe-Flies cover; Right - the Robo-Shoe-Fly is glowing with the number of green and red lights to indicate when its 'needs' were satisfied.

interaction (displayed by the number (1-5) of red LEDs on the left side of the ring). We added this feature in our iteration for internal assessment of the device's functionality (see Fig. 6).

\subsection{Study}

We conducted a preliminary study of the devices with groups of people over several hours in the academic workplace to understand how it might work in a semi-naturalistic setting (so that they experience the interaction as an actual break from work). We recruited participants by reaching out to our department's graduate student mailing list and proposed extra credit for undergraduate student participants (enrolled in an HCI course). Nineteen people signed up, but we were able to test with 13 participants (four graduate and nine undergraduate students) due to scheduling requirements. We divided them into three groups $(2 \mathrm{x}, 4 \mathrm{x}$, and $7 \mathrm{x}$ participants) based on their overlapping schedule availability to afford at least five consecutive hours with other participants. We did not ask participants about their gender, but it happened that in each group it seemed that half were male and half female (except for the seven participants group, which seemed to have three male, and four female participants). We did not plan to compare feedback between groups. We aimed to collect varied qualitative feedback from participants on using the system.

A few participants were familiar with each other from beforehand and two of the graduate students share their lab space regularly. However, none reported pre-existing strong social ties with the rest. The participants wore their creatures for 5 - 7 consecutive hours. We met participants in our lab to provide and collect consent forms. We explained verbally, demoed the interaction (how they should shake their feet, noting that the creatures need to face each other), and set them up with the devices. We attached the devices to the outer side of the participants' right shoes (by threading their shoelaces to secure them, see Fig. 7-Left). We asked them to move a bit with it on and answered questions about its use. We told participants that the creature would let them know by making some sounds and light effects when it needed to interact with other creatures of its kind and move. We explained that it would happen occasionally, and when it did, the creature would like them to find another person with a creature and coordinate foot shaking. We told participants that the creatures would also light up and make sounds to let them know if they were satisfied (this was the only

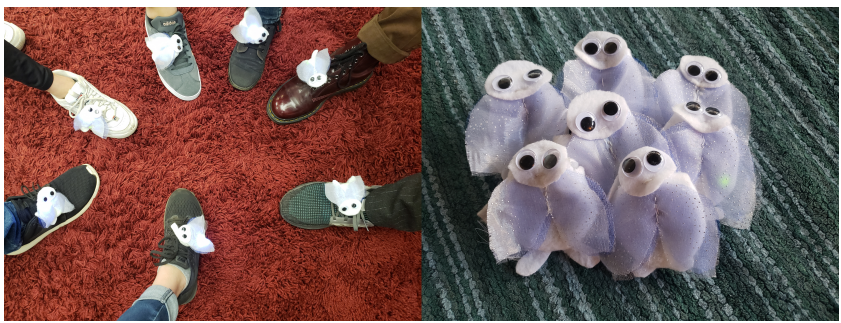

Figure 7: Left - Study participants wearing the Robo-ShoeFlies; Right - The group of Robo-Shoe-Flies covers we created.

fictional backstory we suggested). We also told them they could let the creatures interact even if they didn't signal they needed the interaction yet.

We instructed the participants to work as usual on their projects using their own computer/laptop devices and asked them to pay some attention to their creatures' 'needs' and take care of them. We then let the participants go about their work in our lab space or nearby office spaces. We did not stay to observe participants because we wanted to allow them to feel as natural as possible while they interact with it and with each other.

To collect the participants' feedback we used two strategies: First, immediately at the end of the study sessions, we conducted semi-structured interviews with all the participants individually. The interviews lasted approx. 20 min and we recorded and transcribed them. We focused our questions on: the device (e.g., "What would you change about the device?"); the interaction (e.g., "How did wearing the creature influence your experience today?"); and social interactions (e.g., "How do you think the device impacted social interaction and social experiences, if at all?"). Second, we collected additional feedback from all 13 participants who filled out an online questionnaire confidentially that included nine open-ended questions (e.g., "What did you like about the device?" "What did you like least about using the device?" "Did the device affect the social interactions or communications you had while you were wearing it?") [11].

\subsection{Findings}

We analyzed participants' feedback from the questionnaires and interview transcriptions by applying thematic analysis [73]. We were doing an emergent bottom-up analysis. However, we were also looking for themes related to participants' experience around social interaction (How did people respond to having mixed control over the interaction (needing others to control their device)? How can we encourage people to socialize with other co-located people? Did the fictional backstory of a social network of creatures with 'needs' work to enhance the social experience?)

We found that overall, participants responded to the novel system we built positively. Specific aesthetic design choices we made, such as designing the creatures to feel playful- with a bug-like look with googly eyes and soft fuzzy cover, and designing particular sound tunes and light-animation, contributed to the liking of the overall experience (and to the perception of the creatures as cute and likable companions). However, their location on the shoe and the 
foot-shaking interaction were more controversial - some described it as brief and felt it was not too distracting or demanding. Others thought it was a little awkward to perform the particular footshake movement in public, and one noted that "it tired one leg asymmetrically" (P1)).

All participants (but one) mentioned that the design facilitated co-located social interaction, and the majority also enjoyed aspects of the experience. Some participants particularly liked being encouraged to take breaks and doing so with others. Some liked that they were being nudged to move, and some that it gave them an external reason to socialize and even brought them in contact with new people. Some mentioned how it made them feel more playful and less serious overall. Some commented about how it increased the number of interactions they had with other people (e.g., "interacted with people a lot more than I would on a normal weekday" (P8)) [11].

Participants interpreted fulfilling the actions that tend to the creatures 'needs' mainly as a positive thing. First, they knew that it could indirectly benefit aspects of their wellbeing (e.g., "it gave me some opportunities to take a break and be fun and playful in a way that I like doing but there is not always an opportunity for that" - P11). Second, when participants tended their creature's 'needs,' the device triggered positive expressive feedback in the form of 'happy' light-animation and tunes. This feedback made participants feel that they were being good caregivers (e.g., "I was kind of like excited, I was like oh look it's going to light up soon" (P4)).

Here it is important to note that our study was conducted with a small number of participants, and is not meant to be a summative evaluation of the system design. Rather, it is a preliminary set of qualitative insights, ones that helped to inspire design dimensions that led us to the SST concept.

\section{FROM ROBO-SHOE-FLIES TO SST: SYNTHESIZING DESIGN DIMENSIONS FOR SUPPORTING CO-LOCATED INTERACTION}

Here we synthesize our findings to suggest dimensions that could be valuable when designing systems to support co-located social interaction. Then we explain how these dimensions inspired and informed the development of the Synergistic Social Technology as a strong concept.

\subsection{External Reasons to Socialize}

Many participants mentioned that wearing the creature encouraged them and gave them external reasons to socialize. For example, "[it] gave an excuse or encouraged and increased the amount of time I have interacted with another person for sure" (P5); "it made me take breaks and socialize. Without it, I probably wouldn't have spoken to anyone or left my computer" (P2). Its timer-based interaction was unpredictable. It served as an external trigger for interaction between wearers and their devices and also between wearers. The fictional backstory and interaction design directed wearers' actions. It provided an external call for (inter)action - triggered by the timer. It also provided external reasons to interact with other people, triggered by the 'needs' of the creatures (e.g., "I was kind of using it as an excuse to take a break and jump up and go have a little interaction with people" (P11)). Our design offered a clear guide to action such as taking breaks, getting up from a sitting position, moving in space, coordinating shaking legs, interacting with people. It intervened in the social space proactively [13] by 'nudging' the wearers to interact with that external call. It facilitated that "from the perspective of the wearer (personal) as well as from the perspective of others (social), and the relationship between the two" [13]. Also, the creatures were a conversation piece. They supported participants to initiate conversations. For example, P1 said "it gave me a reason to talk with strangers (beyond small-talk) who also wore the device" (P1). The creatures also served as a conversation starter between participants and people outside the study (e.g., "lots of people not in the study asked about the creature. It was a good talking point”(P8)).

\subsection{Mixed Control, Shared Experience}

The design of our system incorporated the concept of interdependent wearables: people needed to collaborate, coordinate, and share mutual attention. Our findings indicate that people liked having a shared experience. The Robo-Shoe-Flies' backstory of creatures with 'needs' (to meet and move with other creatures) directed wearers to interact, collaborate and coordinate their movements with each other to meet these 'needs' (e.g., 'I think it helps to know that there are other people with this creature so that I can interact with them and we can have that same shared experience, that's really nice" (P12); it made it easier "to connect with everyone else" (P13)). This interdependent interaction was manifested physically in the design (e.g., IR sensing) and conceptually in the backstory. P12 remarked about the value of the interdependent qualities of the interaction. They liked it was "a mutually defined reason to interact with another person" which they identified as "something that is usually absent in everyday life" (P12). The design facilitated a reciprocal kind of interaction between wearers that created a sort of exchange: "to give the gift of time" and "attention" (P10). The interaction encouraged participants to do each other a favor (e.g., "they would be doing you a favor by shaking next to you so [...] you owe them one" (P10)). Some participant also appreciated it directed them to do something with others: "I thought the idea of having it need interaction was a really neat way of both having people interact and having a person interact with it" (P5).

\subsection{Being Playful Together}

Participants described the creatures and the gestures required for interaction as playful. This playfulness made the interactive experience not intimidating (as using a new technology might feel). The design evoked curiosity and a sense of exploration (e.g., "like play with each other throughout the day"( P11)). Participants did not always know if their creatures were satisfied, and some were worried that they needed more interaction. Some creatures never 'nudged' their wearers since their wearer unknowingly already satisfied their need for interactions when they helped another pair (a wearer and their creature). This uncertainty prompted participants to experiment together (e.g., "we had to work as a team to make it stop ringing, so we were like oh, it's your turn, or now it's my turn" (P4)). Some explored ways to care for their creatures that were different from what was instructed in the briefing. For example, one participant said: "I started to think that there was maybe a trick 
[...] but then, because it wasn't triggering sometimes when I thought it should, and I would try other people I would start to think, well maybe you have to go to new people and introduce it to new ones" (P11)). Some participants found the playfulness of the experience to be positive. For instance, P13 said that not many people "connect with each other being goofy nowadays" and that for them "it was a faster way to connect with new people." $\mathrm{P} 5$ described how it facilitates co-located social interaction: "by putting people in slightly awkward situations you facilitate further social interaction in a way." The playfulness also contributed to how the design worked as an icebreaker. For example, P13 commented that by supporting them to be "goofy and vulnerable," it helped "form relationships with new people,". And P2 commented "it's kind of a funny way of having to interact with another person [...] like an icebreaker in a way"' and that "it made the first interaction with everyone else in the group go a little smoother."

\subsection{Beyond the Self: Towards a Shared Low-stakes Goal}

Having a 'dependent' (the wearable creature) to care for was described as a low-stakes goal. It was related to a sense of achievement (e.g. "being able to intermittently complete that goal in the midst of larger and more stressful academic goals, was satisfying" (P12)). Participants described the creatures as "friendly" and "sweet" companions. Caring for them created a sense of responsibility and commitment (e.g., "it created this newfound sense of responsibility, with relatively low-stakes such that it was not anxiety-inducing" (P12)) and fostered a feeling of being needed in some of the wearers. For example, P11 said that they "kept being really concerned that it wasn't getting enough of what it was needing". And P12 said that when the creature signaled it needed interaction while they were busy, it made them feel like they were "neglecting" it. Some participants commented that they felt more aware of their environment and more self-conscious. And although participants wore the creatures for only a few short hours, the experience of wearing and caring for them triggered a sense of "emotional connection" and "purpose". P12 shared that they even prioritized the needs of their creature over their own needs. They told us that as they opened the restroom door (after not going for a long time), the creature expressed their need for interaction. P12 responded by immediately turning back around to find the other wearer and take care of their creature (e.g., "I haven't used the bathroom all day, and I went back, I was like I have to do this" (P12)). Lastly, participants were also working together towards the shared goal of caring for their creatures (e.g., "we were working together to keep our creatures happy" (P10)).

\subsection{How the SST's Core Principles Emerged from the Robo-Shoe-Flies Case Study}

Here we discuss how the core principles of the SST emerged from our RtD process of the Robo-Shoe-Flies. In Fig. 8 we relate our system design to the design dimensions (which we formed based on synthesizing findings from our case study) to show how we developed the core SST principles. Our Robo-Shoe-Flies system prototype had a fictional backstory of creatures who dwell on people's feet and 'need' to interact with other creatures of their species

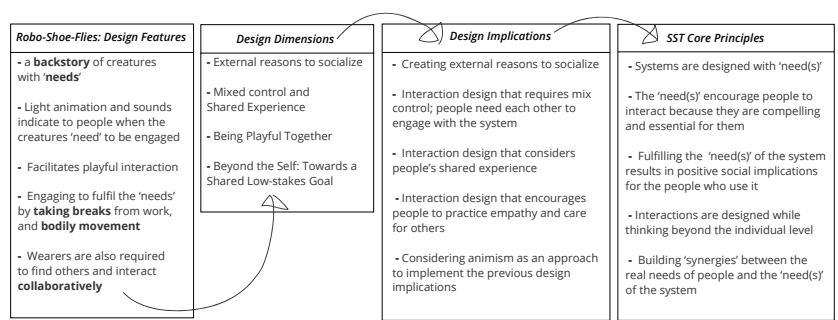

Figure 8: This figure demonstrates how the SST concept emerged in the RtD process of the Robo-Shoe-Flies case study.

by moving together. This backstory of creatures with 'needs' enabled us to design interaction around a simulated inner life that suggested compelling and essential interactions. It created synergies between the system's 'needs' and people's (presumed need) to engage in social interaction.

The backstory created an external reason for the wearer to engage with it and with other wearers. Our system employs vulnerability strategically by using the fictional backstory to guide the wearers to interact with others. Vulnerability is present on two levels: the creatures 'need' interaction with other creatures and depend on their wearers to achieve this interaction. The creatures are vulnerable because they need other creatures. They also rely on their wearers to be able to fulfill this need. The wearers practice being empathetic to their creatures 'needs.' However, when they want to help their creatures they rely on other wearers to coordinate meetings and move together. This engages the wearers' sense of vulnerability as they depend on others' willingness to collaborate with them. These 'needs' provided an external reason for wearers to socialize as the system suggested wearers work with others towards a shared goal. It also relates to the concept of interdependent wearables: wearers were keener to interact with each other because they needed others to help them care for their wearable creatures. The mixed control supported a shared experience. Caring for their creatures together created a pre-agreed upon invitation to interact (e.g. "I think people were more easily talking to me cause like we had a task that we had to do together and it doesn't work if you don't do it together" (P4)). It also had sociospatial implications, for example, P1 felt the need to stay close to other creatures, and P8 said that they stayed in proximity to other creatures to take care of their creature.

Our system introduced a synergy between the creatures' social 'need' and its possible effect on wearers' social interaction. It focused the interaction beyond the individual and towards a shared low-stakes goal and implied three types of relations. First, a relationship between each wearer and their creature - through the synergistic quality of the interaction design, two HRI paradigm converged: the wearer cared for their creature while the creature supported them to engage in presumably beneficial activities. Thus it created a combination of the caretaker paradigm with the assistant/companion paradigm. The Robo-shoe-flies system shifted participants' mindset from focusing on themselves to caring for their companions (e.g., "it takes you away and out of that mindset of being by yourself [...] it makes you attend to something else" (P5)). The second relation is that between the creatures and the wearers as two small collectives, 
the wearers became one community of people who collaborated to fulfill their creatures' needs together. Finally, and most importantly, the relationships between wearers developed, as they coordinated their actions towards a shared goal to satisfy the needs of their creatures. The wearers became a small community of carers who could benefit from their shared responsibility. Participants expressed how they felt dedicated to caring for their creatures-individually as well as collectively (e.g., "everyone would just pay attention to the creatures and everyone were shaking their foot even if theirs wasn't [needing the interaction]” (P13)).

\section{HOW SST IS MANIFESTED IN OTHER DESIGNS}

The case study of the Robo-Shoe-Flies prototype provides one example of the Synergistic Social Technology concept in action. Ideally, a strong concept should be vertically grounded in several exemplar systems or instances [29]. Here we present a few more examples of systems that relate to SST and embody some aspects of it, to varying degrees. In Fig. 9 we demonstrate where the designs relate and where they deviate from SST.

Data Hungry Home (DHH) [39] is a framing for several design concepts that propose a collaborative relationship between humans and objects fuelled by data. In this framing, the humans are in charge of collecting data while the objects 'need' to 'eat' the "foodata". It is "an ecosystem where data needs to be produced and consumed to maintain the system" [39]. The DHH design proposes that objects could have a 'hunger' which "can be a need, craving, desire, dependency, reliance, even an addiction or simply seeking enough sustenance to plod along" [40]. This example evokes the metaphor of animism and has the synergistic qualities of SST through its focus on objects and their dependency on a human to be 'fed'. Similarly to SST the 'needs' of the objects drive the interaction. But the 'needs' in $\mathrm{DHH}$ are mapped 1:1 between the object and the human who is feeding it "You scratch my back (with data/knowledge) and I will scratch your back (with an interaction), so to speak" [40]. The DHH is focused only on the relationship of a single human and their objects, and therefore lacks the social quality of SST. In contrast, the SST concept proposes that the artifact or system have a 'need' which, when it gets fulfilled, has social implications: humans interacting with other humans collaboratively.

Tamagotchi [3], is a commercial example. It is a simple computationally-based display of a virtual pet enclosed in a small plastic device. It is connected to a keychain and needs daily interaction with its users for it to 'improved and grow.' It requires continuous care, or else it 'dies.' The Tamagotchi Connection [64] is an addition from 2004 that lets different Tamagotchi devices interact with each other via infrared sensing. However, these devices were not designed to encourage different users to interact with each other directly. Rather, one user could have a few Tamagotchi devices and let them connect with each other. These Tamagotchi designs primarily focus on the interaction between a single human and their multiple devices, similar to DHH. Therefore this design lacks the social quality of SST.

Snapchat app, is an example of a system that embodies the social aspect of SST but does not include the metaphor of animism. Its interface design is highly visual and challenging. It meant that people engaged with others in-person to show them how to use it - "Snapchat had a confusing interface, so users in high school and college frequently showed each other how to use new features and navigate the app. [...] This in-person sharing helped Snapchat grow quickly among young people" [24]. This example demonstrates how interface design could have social implications. However, the collaboration between people to learn how to use the interface is not a requirement of the system design. Therefore, it is not clear if these social implications were inadvertent results or intentionally designed.

Social media platforms in general relate to SST. Often, these systems are designed to rely on people (or need people) to create their content (e.g., Twitter, Facebook, Instagram, etc.). When people begin to interact with others by commenting, sharing, liking, shopping, and so on, there are synergies between the 'need' of the system for content creation and the resulting social interaction people using the system experience between themselves and others. These systems need humans to act in certain ways to sustain themselves, and the results of these actions have social implications relating to how the human-users interact with others. Hence the design of social media platforms includes synergistic-social aspects. However, the needs for these systems are not embedded in metaphors of animism and do not require synchronous collaboration between the humans who use them.

Lågom [14] are social wearables designed as a flower-like species with a backstory that explains that they 'thrive' based on balancing wearers' speaking participation levels in a group discussion. This design instance embodies both the synergistic-social and the metaphor of animism. The Lågom have a fictional backstory establishing that people who wear them need to collaborate as a group, adapting their conversation style to help the species to thrive. When people engaged in a group discussion with other Lågom wearers and fulfilled their 'need' for a balanced participation level in the group's discussion, the wearers themselves could benefit from a more 'balanced' conversation as well. The Lågom design suggests a synergy between the 'needs' of the system and the benefiting people. The people who wear the Lågom are directed to work together collaboratively to meet their 'needs,' and tending to these 'needs' has social implications for the people using the system (in this case, adapting conversation styles during a group discussion).

Our search to find more design instances and systems to ground the concept even deeper yielded limited results. While there are a number of such systems, we found a lack of examples that fully embody SST's core aspects. We believe this gap is an interesting area for future design explorations.

\begin{tabular}{|c|c|c|c|c|c|c|}
\hline Core SST principles & DHH & Tamagotchi & $\begin{array}{c}\text { Snapchat App } \\
\text { interface }\end{array}$ & $\begin{array}{c}\text { Social media } \\
\text { platforms }\end{array}$ & Lảgom & Robo-Shoe-Flies \\
\hline Syystems designed with 'need(s)' & r & r & $\mathrm{N}$ & $\mathrm{N}$ & $\mathrm{r}$ & $\mathrm{r}$ \\
\hline $\begin{array}{l}\text { The 'needss' encourage people using the } \\
\text { system to interact }\end{array}$ & ? & $\mathrm{N}$ & r & r & r & r \\
\hline $\begin{array}{l}\text { Fulfiling the system's' need(s)' results in } \\
\text { positive social implications }\end{array}$ & N & $\mathrm{N}$ & r & r & r & $\mathrm{r}$ \\
\hline $\begin{array}{l}\text { Interactions are designed while thinking } \\
\text { beyond the individual level of if iteraction }\end{array}$ & $\mathrm{N}$ & $\mathrm{N}$ & r & y & r & r \\
\hline 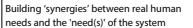 & ? & Y & $?$ & $\mathrm{Y}$ & Y & Y \\
\hline
\end{tabular}

Figure 9: Table showing a list of the design examples and whether or not they include each of the core SST principles. 


\section{DISCUSSION}

In their paper defining strong concepts, Höök and Lowgren write: "Elements of that particular or instance, can be isolated and abstracted to the level that they are applicable in a whole class of applications, a whole range of use situations, or a whole genre of designs" [29]. The SST concept emerged through the RtD process of the RoboShoe-Flies prototype. The design dimensions we formed (based on synthesizing findings from our study) helped us abstract its elements and articulate how the SST core principles were developed. Even though our system had anthropomorphic features (such as 'eyes'), we found it better to characterize SST with animism, rather than anthropomorphism. We believe this allows for a broader range of potential synergies and relations to emerge in future design work.

A range of related $\mathrm{HCI}$ theoretical frames to SST were detailed in this paper (e.g., vulnerability [12], interdependent wearables [33], OOO [28]). However, what makes this concept "novel" and "contestable" [29] to the interaction-design research community, and different from the other concepts and HCI theory we described, is that it combines perspectives and qualities. It combines collectiveminded and animistic perspectives with qualities of interdependence and vulnerability. SST proposes a new direction: designing systems in which humans and technology work together in a synergistic-social manner to drive positive social implications.

The notion of synergistic social technology could be a piece of the puzzle for situations that require designing systemic changes. For example, in broader societal issues such as designing systems that create collective accountability or even feelings of collective connectedness. Technology designs aiming to solve 'wicked problems' such as climate change, political discord, and economic inequality could benefit from thinking at this collective level in design. Another area that might benefit from SST is educational technology design that wants to support the growth of social-emotional skills in children (and adults who may need more scaffolding). Synergistic social systems could support learners in practicing their socio-emotional skills with one another toward increased understanding and mastery.

Designers and researchers could appropriate SST as an element in their potential design solutions or when creating new design instances. For example, designing systems from an individual point of view may evoke feelings of isolation or shame. Some popular social media platforms are accused of causing harm [42] instead of bringing people closer together and building community and connection as they hope to. However, if we design from a collective socio-emotional perspective, perhaps it would foster different feelings. It is in line with the notion of 'Suprahuman' design [32], which suggests taking up alternative design values aimed at shaping the space between people, rather than focusing primarily on meeting an aggregation of individual needs.

A possible negative aspect of SST relates to the challenges designers would face with identifying appropriate synergism. Designers' perspective about what is synergistic and beneficial for people could be limited, especially given unanticipated contexts. People may vary in their appreciation of or interest in engaging with technology inspired by SST. Therefore, designers should consider such limitations and include ways to empower people to adjust the design according to their context of use and personal preferences. No outright assumptions should be made about the kind of interaction that is positive, wanted, and always beneficial for people. For example, the value of "connection with others" is not always good. Every design value should always be considered and evaluated in its relevant context.

Designers should be mindful of possible ethical implications when considering exploring SST in their work. They should reflect on potential unintended consequences- and introduce such designs when convinced it is appropriate - to avoid manipulating people or creating unwanted social pressure to interact when one is uncomfortable or uninterested. Designers need to be aware that there could also be possible negative impacts to their design, especially when used repeatedly over long periods (e.g., stigmatization, induced stress, work interruptions, etc.).

Reflective [67] and responsible design [51] approaches could help tackle some of the ethical challenges and limitations of SSTinspired work- especially when it relates to design for societal challenges. It could also be helpful when considering the novelty or potential future over-ubiquity of new artifacts (that could cause large amounts of electronic waste should they become trendy) and a range of other possible consequences, positive and negative.

\section{LIMITATIONS}

The theoretical framing of the SST concept emerged from the RtD process of the Robo-Shoe-Flies prototype. We studied the design with participants over a short period of use. Therefore we cannot assess the possibility of novelty effects wearing off as people experience them over long periods of time. Furthermore, we conducted the study within the context of a workplace/educational institution. It would be interesting to instantiate the SST concept in designs for other domains as well, with the caveat that one might encounter unforeseen boundaries or challenges along the way.

Our initial plan was to iterate and retest the design in subsequent studies. That plan was hampered by the arrival of COVID-19, making it impossible to conduct further detailed observations. However, as we synthesized design dimensions from our case study, the concept began to unveil itself. We found it inspiring enough to fully formalize its principles even though we could not evaluate them yet. Newly articulated strong concepts are considered provisional [29]. Here we propose the SST as a strong concept: as a generative piece of knowledge, which could inspire future applications that seek "new solutions for a particular design situation" [29]. Therefore, because this concept is new, its influence on the field of interaction design is not yet clear. It could only be evaluated over time.

\section{CONCLUSION}

Through design, prototyping, and study of our Robo-Shoe-Flies system, we arrived at an intermediate-level knowledge [44] contribution: proposing the Synergistic Social Technology (SST) as a strong concept for design [29]. SST suggests that when technologies have their own 'needs' for interaction this could motivate people to engage with the tech. Also, and more importantly, it could encourage them to engage with others synchronously and collaboratively. In the process of the technology getting its 'needs' met, people who use the 
system benefit from social interaction, hence the synergistic-social quality. The SST concept has five core principles:

- Systems designed with 'needs.'

- The 'needs' encourage people using the system to interact.

- Fulfilling the system's 'need' results in positive social implications.

- Interactions are designed while thinking beyond the individual level of interaction.

- Building 'synergies' between real human needs and the 'needs' of the system

We articulated the concept based on theoretical frames (horizontal grounding) and vertical grounding by describing other systems that share some aspects of SST (e.g., the Data Hungry Home [40], Morse Things [77], Lågom [14]). We discussed some key application areas of HCI that might benefit from this strong concept. In particular, design situations that require systemic changes that need to take place across communities. We presented the case study of the Robo-Shoe-Flies to scaffold how the SST emerged from the RtD process. We included design-focused observations based on a study of this system through the presentation of the design dimensions: (i) being playful together, (ii) external reasons to interact, (iii) mix control and shared experience, and (iv) interactions beyond the self. We hope the SST concept and these observations may inspire other designers and researchers interested in developing technology to positively impact social interaction, not just from an individual perspective but also from a collective perspective across devices and multiple users.

\section{ACKNOWLEDGMENTS}

We thank our study participants for their feedback and the Science Internship Program (SIP) interns: Rachel Hsiao, Sanoja Kikkeri, Charlene Hoang, and Eleanor Bangs for their support in developing the design prototype. We thank Peter Cottrell and James Fey for their technical support and feedback. We thank Kia Höök and Ferran Altarriba Bertran for their valuable feedback. We also want to thank members of the PhD-Design mailing list who discussed SST-related concepts in a thread. Finally, we thank our reviewers for their thoughtful comments and suggestions.

\section{REFERENCES}

[1] 2019. Bcon. https://bcon.zone/

[2] 2019. Cybershoes. https://www.cybershoes.io/

[3] 2019. Tamagotchi. https://en.wikipedia.org/w/index.php?title=Tamagotchi\& oldid=930819711 Page Version ID: 930819711.

[4] 2020. Fitbit Official Site for Activity Trackers. https:/www.fitbit.com/global/us/ home

[5] Ferran Altarriba Bertran, Elena Márquez Segura, and Katherine Isbister. 2020 Technology for Situated and Emergent Play: A Bridging Concept and Design Agenda. In Proceedings of the 2020 CHI Conference on Human Factors in Computing Systems (Honolulu, HI, USA) (CHI '20). Association for Computing Machinery, New York, NY, USA, 1-14. https://doi.org/10.1145/3313831.3376859

[6] Apple. 2020. Apple Watch. https://www.apple.com/watch/

[7] Cynthia Breazeal, Atsuo Takanishi, and Tetsunori Kobayashi. 2008. Social robots that interact with people. Springer handbook of robotics (2008), 1349-1369.

[8] Brené Brown. 2015. Daring greatly: How the courage to be vulnerable transforms the way we live, love, parent, and lead. Penguin.

[9] Sunny Consolvo, Katherine Everitt, Ian Smith, and James A Landay. 2006. Design requirements for technologies that encourage physical activity. In Proceedings of the SIGCHI conference on Human Factors in computing systems. 457-466.

[10] Alma Leora Culén, Jorun Børsting, and William Odom. 2019. Mediating Relatedness for Adolescents with ME: Reducing Isolation through Minimal Interactions with a Robot Avatar. In Proceedings of the 2019 on Designing Interactive Systems Conference. ACM, 359-371.

[11] Ella Dagan, James Fey, Sanoja Kikkeri, Charlene Hoang, Rachel Hsiao, and Katherine Isbister. 2020. Flippo the Robo-Shoe-Fly: A Foot Dwelling Social Wearable Companion. In Extended Abstracts of the 2020 CHI Conference on Human Factors in Computing Systems (Honolulu, HI, USA) (CHI EA '20). Association for Computing Machinery, New York, NY, USA, 1-10. https://doi.org/10.1145/3334480.3382928

[12] Ella Dagan, Elena Márquez Segura, Ferran Altarriba Bertran, Miguel Flores, and Katherine Isbister. 2019. Designing 'True Colors': A Social Wearable That Affords Vulnerability. In Proceedings of the 2019 CHI Conference on Human Factors in Computing Systems (Glasgow, Scotland Uk) (CHI '19). ACM, New York, NY, USA, Article 33, 14 pages. https://doi.org/10.1145/3290605.3300263

[13] Ella Dagan, Elena Márquez Segura, Ferran Altarriba Bertran, Miguel Flores, Robb Mitchell, and Katherine Isbister. 2019. Design Framework for Social Wearables. In Proceedings of the 2019 on Designing Interactive Systems Conference (San Diego, CA, USA) (DIS '19). ACM, New York, NY, USA, 1001-1015. https://doi.org/10. $1145 / 3322276.3322291$

[14] Ella Dagan, Elena Márquez Segura, Miguel Flores, and Katherine Isbister. 2018. 'Not Too Much, Not Too Little' Wearables For Group Discussions. In Extended Abstracts of the 2018 CHI Conference on Human Factors in Computing Systems (Montreal QC, Canada) (CHI EA '18). ACM, New York, NY, USA, Article LBW129, 6 pages. https://doi.org/10.1145/3170427.3188500

[15] Kerstin Dautenhahn. 2007. Socially intelligent robots: dimensions of humanrobot interaction. Philosophical transactions of the royal society B: Biological sciences 362, 1480 (2007), 679-704.

[16] Maria Puig de La Bellacasa. 2011. Matters of care in technoscience: Assembling neglected things. Social studies of science 41, 1 (2011), 85-106.

[17] Sam Draper. 2018. GTX Corp Debuts SmartSole and Invisabelt GPS Trackers for Children. https://www.wearable-technologies.com/2018/07/gtx-corp-debutssmartsole-and-invisabelt-gps-trackers-for-children

[18] Sam Draper. 2018. Puma is Bringing Back its 80s Smart Shoe with Updated Technology. https://www.wearable-technologies.com/2018/12/puma-is-bringingback-its-80s-smart-shoe-with-updated-technology/

[19] Daniel A. Epstein, Daniel Avrahami, and Jacob T. Biehl. 2016. Taking 5: WorkBreaks, Productivity, and Opportunities for Personal Informatics for Knowledge Workers. In Proceedings of the 2016 CHI Conference on Human Factors in Computing Systems (San Jose, California, USA) (CHI '16). ACM, New York, NY, USA, 673-684. https://doi.org/10.1145/2858036.2858066

[20] Yasmin Felberbaum and Joel Lanir. 2018. Better Understanding of Foot Gestures: An Elicitation Study. In Proceedings of the 2018 CHI Conference on Human Factors in Computing Systems (Montreal QC, Canada) (CHI '18). ACM, New York, NY, USA, Article 334, 12 pages. https://doi.org/10.1145/3173574.3173908

[21] Hayden Field. 2018. Add Years to Your Life with These 4 "Work Break" Apps. https://www.entrepreneur.com/article/313416

[22] Terrence Fong, Illah Nourbakhsh, and Kerstin Dautenhahn. 2003. A survey of socially interactive robots. Robotics and autonomous systems 42, 3-4 (2003), 143-166.

[23] Batya Friedman, Peter Kahn, and Alan Borning. 2002. Value sensitive design: Theory and methods. University of Washington technical report 2-12 (2002).

[24] Billy Gallagher. 2018. How to Turn Down a Billion Dollars: The Snapchat Story. St. Martin's Press.

[25] William Gaver. 2012. What Should We Expect from Research Through Design?. In Proceedings of the SIGCHI Conference on Human Factors in Computing Systems (Austin, Texas, USA) (CHI '12). ACM, New York, NY, USA, 937-946. https: //doi.org/10.1145/2207676.2208538

[26] grealisisters. 2018. Foot Shake dance TUTORIAL! https://www.youtube.com/ watch?v=VgFI15oVRrM

[27] Graham Harman. 2010. Towards speculative realism: Essays and lectures. John Hunt Publishing.

[28] Graham Harman. 2018. Object-oriented ontology: A new theory of everything. Penguin UK.

[29] Kristina Höök and Jonas Löwgren. 2012. Strong Concepts: Intermediate-Level Knowledge in Interaction Design Research. ACM Trans. Comput.-Hum. Interact. 19, 3, Article 23 (Oct. 2012), 18 pages. https://doi.org/10.1145/2362364.2362371

[30] Adafruit Industries. 2020. Circuit Playground Express. https://www.adafruit. com/product $/ 3333$

[31] Katherine Isbister. 2006. Better game characters by design: A psychological approach. CRC Press.

[32] Katherine Isbister. 2019. Toward 'Suprahuman' Technology. In Proceedings of the Half way to the Future Symposium 2019 (Nottingham, United Kingdom) (HTTF 2019). Association for Computing Machinery, New York, NY, USA, Article 24, 4 pages. https://doi.org/10.1145/3363384.3363468

[33] Katherine Isbister, Kaho Abe, and Michael Karlesky. 2017. Interdependent Wearables (for Play): A Strong Concept for Design. In Proceedings of the 2017 CHI Conference on Human Factors in Computing Systems (Denver, Colorado, USA) (CHI '17). ACM, New York, NY, USA, 465-471. https://doi.org/10.1145/3025453.3025939 
[34] Hao Jiang, Siyuan Lin, Veerajagadheswar Prabakaran, Mohan Rajesh Elara, and Lingyun Sun. 2019. A Survey of Users' Expectations Towards On-body Companion Robots. In Proceedings of the 2019 on Designing Interactive Systems Conference ACM, 621-632.

[35] Hsin-Liu (Cindy) Kao, Deborah Ajilo, Oksana Anilionyte, Artem Dementyev, Inrak Choi, Sean Follmer, and Chris Schmandt. 2017. Exploring Interactions and Perceptions of Kinetic Wearables. In Proceedings of the 2017 Conference on Designing Interactive Systems (Edinburgh, United Kingdom) (DIS '17). Association for Computing Machinery, New York, NY, USA, 391-396. https://doi.org/10. 1145/3064663.3064686

[36] Reuben Kirkham, Sebastian Mellor, David Green, Jiun-Shian Lin, Karim Ladha, Cassim Ladha, Daniel Jackson, Patrick Olivier, Peter Wright, and Thomas Ploetz. 2013. The Break-time Barometer: An Exploratory System Forworkplace Breaktime Social Awareness. In Proceedings of the 2013 ACM International foint Conference on Pervasive and Ubiquitous Computing (Zurich, Switzerland) (UbiComp '13). ACM, New York, NY, USA, 73-82. https://doi.org/10.1145/2493432.2493468

[37] Suzanne LaBarre and Suzanne LaBarre. 2010. Almost Genius: Robotic Arm Cuff Works Like a Wearable Therapist. https://www.fastcompany.com/1662830/ almost-genius-robotic-arm-cuff-works-like-a-wearable-therapist

[38] Amanda Lazar, Hilaire J Thompson, Anne Marie Piper, and George Demiris. 2016 Rethinking the design of robotic pets for older adults. In Proceedings of the 2016 ACM Conference on Designing Interactive Systems. ACM, 1034-1046.

[39] Matthew Lee-Smith. 2020. The Data Hungry Home: Humans Harvesting Data for Living Devices. In Companion Publication of the 2020 ACM Designing Interactive Systems Conference (Eindhoven, Netherlands) (DIS' 20 Companion). Association for Computing Machinery, New York, NY, USA, 527-535. https://doi.org/10. 1145/3393914.3395832

[40] Matthew Lee-Smith, Tracy Ross, Martin Maguire, Fung Po Tso, Jeremy Morley, and Stefano Cavazzi. 2019. The Data Hungry Home. In Proceedings of the Halfway to the Future Symposium 2019 (Nottingham, United Kingdom) (HTTF 2019). Association for Computing Machinery, New York, NY, USA, Article 6, 10 pages. https://doi.org/10.1145/3363384.3363390

[41] Brian Y. Lim, Aubrey Shick, Chris Harrison, and Scott E. Hudson. 2011. Pediluma: Motivating Physical Activity Through Contextual Information and Social Influence. In Proceedings of the Fifth International Conference on Tangible, Embedded, and Embodied Interaction (Funchal, Portugal) (TEI '11). ACM, New York, NY, USA, 173-180. https://doi.org/10.1145/1935701.1935736

[42] Myungsuh Lim and Yoon Yang. 2015. Effects of users' envy and shame on social comparison that occurs on social network services. Computers in Human Behavior 51 (2015), 300-311.

[43] Joseph Lindley, Paul Coulton, and Rachel Cooper. 2017. Why the internet of things needs object orientated ontology. The Design fournal 20, sup1 (2017), S2846-S2857.

[44] Jonas Löwgren. 2013. Annotated Portfolios and Other Forms of IntermediateLevel Knowledge. Interactions 20, 1 (Jan. 2013), 30-34. https://doi.org/10.1145/ 2405716.2405725

[45] Andrés Lucero, Evangelos Karapanos, Juha Arrasvuori, and Hannu Korhonen. 2014. Playful or Gameful? Creating delightful user experiences. interactions 21, 3 (2014), 34-39.

[46] Michal Luria, Guy Hoffman, and Oren Zuckerman. 2017. Comparing Social Robot, Screen and Voice Interfaces for Smart-Home Control. In Proceedings of the 2017 CHI Conference on Human Factors in Computing Systems (Denver, Colorado, USA) (CHI '17). Association for Computing Machinery, New York, NY, USA, 580-628. https://doi.org/10.1145/3025453.3025786

[47] Zhihan Lv, Shengzhong Feng, Muhammad Sikandar Lal Khan, Shafiq Ur Réhman, and Haibo Li. 2014. Foot Motion Sensing: Augmented Game Interface Based on Foot Interaction for Smartphone. In CHI '14 Extended Abstracts on Human Factors in Computing Systems (Toronto, Ontario, Canada) (CHI EA '14). ACM, New York, NY, USA, 293-296. https://doi.org/10.1145/2559206.2580096

[48] Sonja Lyubomirsky. 2008. The how of happiness: A scientific approach to getting the life you want. Penguin.

[49] Elena Márquez Segura, James Fey, Ella Dagan, Samvid Niravbhai Jhaveri, Jared Pettitt, Miguel Flores, and Katherine Isbister. 2018. Designing Future Social Wearables with Live Action Role Play (Larp) Designers. In Proceedings of the 2018 CHI Conference on Human Factors in Computing Systems (Montreal QC, Canada) (CHI '18). ACM, New York, NY, USA, Article 462, 14 pages. https: //doi.org/10.1145/3173574.3174036

[50] Elena Márquez Segura, Laia Turmo Vidal, Asreen Rostami, and Annika Waern. 2016. Embodied Sketching. In Proceedings of the 2016 CHI Conference on Human Factors in Computing Systems (San Jose, California, USA) (CHI '16). Association for Computing Machinery, New York, NY, USA, 6014-6027. https://doi.org/10. $1145 / 2858036.2858486$

[51] Gavin Melles, Ian de Vere, and Vanja Misic. 2011. Socially responsible design thinking beyond the triple bottom line to socially responsive and sustainable product design. CoDesign 7, 3-4 (2011), 143-154.

[52] Caitlin Mullen. 2019. Millennials can't get a (lunch) break. https: //www.bizjournals.com/bizwomen/news/latest-news/2019/06/millennialscant-get-a-lunch-break.html
[53] Florian Müller, Joshua McManus, Sebastian Günther, Martin Schmitz, Max Mühlhäuser, and Markus Funk. 2019. Mind the Tap: Assessing Foot-Taps for Interacting with Head-Mounted Displays. In Proceedings of the 2019 CHI Conference on Human Factors in Computing Systems (Glasgow, Scotland Uk) (CHI '19). ACM, New York, NY, USA, Article 477, 13 pages. https://doi.org/10.1145/3290605.3300707

[54] W. Kerry Mummery, Grant M. Schofield, Rebekah Steele, Elizabeth G. Eakin, and Wendy J. Brown. 2005. Occupational Sitting Time and Overweight and Obesity in Australian Workers. American fournal of Preventive Medicine 29, 2 (Aug 2005), 91-97. https://doi.org/10.1016/j.amepre.2005.04.003

[55] Thomas Olsson, Pradthana Jarusriboonchai, Paweł Woźniak, Susanna Paasovaara, Kaisa Väänänen, and Andrés Lucero. 2019. Technologies for enhancing collocated social interaction: review of design solutions and approaches. Computer Supported Cooperative Work (CSCW) (2019), 1-55.

[56] Neil Patel. 2014. When, How, and How Often to Take a Break. https://www.inc. com/neil-patel/when-how-and-how-often-to-take-a-break.html

[57] Dorian Peters, Rafael A Calvo, and Richard M Ryan. 2018. Designing for motivation, engagement and wellbeing in digital experience. Frontiers in psychology 9 (2018), 797.

[58] Sarah M Rabbitt, Alan E Kazdin, and Brian Scassellati. 2015. Integrating socially assistive robotics into mental healthcare interventions: Applications and recommendations for expanded use. Clinical psychology review 35 (2015), 35-46.

[59] Sarah Reeder, Lorelei Kelly, Bobak Kechavarzi, and Selma Sabanovic. 2010. Breakbot: a social motivator for the workplace. In Proceedings of the 8th ACM Conference on Designing Interactive Systems. ACM, 61-64.

[60] Cathy Russey. 2019. Alphabet's Verily Developing Health-Tracking Smart Shoes that Can Measure Weight and Detect Falls. https://www.wearabletechnologies.com/2019/02/alphabets-verily-developing-health-tracking-smartshoes-that-can-measure-weight-and-detect-falls/

[61] William Saunders and Daniel Vogel. 2016. Tap-Kick-Click: Foot Interaction for a Standing Desk. In Proceedings of the 2016 ACM Conference on Designing Interactive Systems (Brisbane, QLD, Australia) (DIS '16). ACM, New York, NY, USA, 323-333. https://doi.org/10.1145/2901790.2901815

[62] Dennis Schleicher, Peter Jones, and Oksana Kachur. 2010. Bodystorming as embodied designing. interactions 17, 6 (2010), 47-51.

[63] Dominik Schmidt, Raf Ramakers, Esben W. Pedersen, Johannes Jasper, Sven Köhler, Aileen Pohl, Hannes Rantzsch, Andreas Rau, Patrick Schmidt, Christoph Sterz, Yanina Yurchenko, and Patrick Baudisch. 2014. Kickables: Tangibles for Feet. In Proceedings of the 32Nd Annual ACM Conference on Human Factors in Computing Systems (Toronto, Ontario, Canada) (CHI '14). ACM, New York, NY, USA, 3143-3152. https://doi.org/10.1145/2556288.2557016

[64] Eric Schweikardt and Mark D Gross. 2007. A brief survey of distributed computational toys. In 2007 First IEEE International Workshop on Digital Game and Intelligent Toy Enhanced Learning (DIGITEL'07). IEEE, 57-64.

[65] Elena Márquez Segura and Katherine Isbister. 2015. Enabling co-located physical social play: A framework for design and evaluation. In Game user experience evaluation. Springer, 209-238.

[66] Meg Selig. 2017. How Do Work Breaks Help Your Brain? 5 Surprising Answers. https://www.psychologytoday.com/blog/changepower/201704/how-dowork-breaks-help-your-brain-5-surprising-answers

[67] Phoebe Sengers, Kirsten Boehner, Shay David, and Joseph 'Jofish' Kaye. 2005. Reflective Design. In Proceedings of the 4th Decennial Conference on Critical Computing: Between Sense and Sensibility (Aarhus, Denmark) (CC'05). Association for Computing Machinery, New York, NY, USA, 49-58. https://doi.org/10.1145/ 1094562.1094569

[68] Michelle Takemoto, Brittany Lewars, Samantha Hurst, Katie Crist, Camille Nebeker, Hala Madanat, Jeanne Nichols, Dori E Rosenberg, and Jacqueline Kerr. 2018. Participants' perceptions on the use of wearable devices to reduce sitting time: Qualitative analysis. $7 M I R$ mHealth and uHealth 6, 3 (2018), e73.

[69] Wendell C. Taylor. 2005. Transforming Work Breaks to Promote Health. American fournal of Preventive Medicine 29, 5 (Dec 2005), 461-465. https://doi.org/10.1016/ j.amepre.2005.08.040

[70] Wendell C Taylor. 2011. Booster Breaks: an easy-to-implement workplace policy designed to improve employee health, increase productivity, and lower health care costs. Journal of Workplace Behavioral Health 26, 1 (2011), 70-84.

[71] Oscar Tomico and Danielle Wilde. 2015. Soft, Embodied, Situated and Connected. In Proceedings of the 17th International Conference on Human-Computer Interaction with Mobile Devices and Services Adjunct (Copenhagen, Denmark) (MobileHCI '15). Association for Computing Machinery, New York, NY, USA, 1179-1186. https://doi.org/10.1145/2786567.2794351

[72] Nynke Tromp, Paul Hekkert, and Peter-Paul Verbeek. 2011. Design for socially responsible behavior: a classification of influence based on intended user experience. Design issues 27, 3 (2011), 3-19.

[73] Anthony G Tuckett. 2005. Applying thematic analysis theory to practice: A researcher's experience. Contemporary nurse 19, 1-2 (2005), 75-87.

[74] Philip Van Allen, Joshua McVeigh-Schultz, Brooklyn Brown, Hye Mi Kim, and Daniel Lara. 2013. AniThings: animism and heterogeneous multiplicity. In CHI'13 Extended Abstracts on Human Factors in Computing Systems. 2247-2256. 
[75] Eduardo Velloso, Dominik Schmidt, Jason Alexander, Hans Gellersen, and An dreas Bulling. 2015. The Feet in Human-Computer Interaction: A Survey of Foot-Based Interaction. ACM Comput. Surv. 48, 2, Article 21 (Sept. 2015), 35 pages. https://doi.org/10.1145/2816455

[76] Benjamin N. Waber, Daniel Olguin Olguin, Taemie Kim, and Alex Pentland. 2010 Productivity Through Coffee Breaks: Changing Social Networks by Changing Break Structure. Number ID 1586375. https://papers.ssrn.com/abstract $=1586375$

[77] Ron Wakkary, Doenja Oogjes, Sabrina Hauser, Henry Lin, Cheng Cao, Leo Ma, and Tijs Duel. 2017. Morse Things: A Design Inquiry into the Gap Between Things and Us. In Proceedings of the 2017 Conference on Designing Interactive Systems (Edinburgh, United Kingdom) (DIS '17). Association for Computing Machinery, New York, NY, USA, 503-514. https://doi.org/10.1145/3064663.3064734
[78] Lisa Wiese, Anna Pohlmeyer, and Paul Hekkert. 2019. Activities as a Gateway to Sustained Subjective Well-Being Mediated by Products. In Proceedings of the 2019 on Designing Interactive Systems Conference. ACM, 85-97.

[79] Patrycja Zdziarska, Felix A. Epp, Walther Jensen, Mark D. Gross, and Ellen YiLuen Do. 2019. Hooze: A Kinetic Fashion Accessory for Touch and Play. In Proceedings of the Thirteenth International Conference on Tangible, Embedded, and Embodied Interaction (Tempe, Arizona, USA) (TEI '19). Association for Computing Machinery, New York, NY, USA, 407-413. https://doi.org/10.1145/3294109.3300980

[80] Ye Zheng, Matthew McCaleb, Courtney Strachan, and Betsy Williams. 2012. Exploring a Virtual Environment by Walking in Place Using the Microsoft Kinect. In Proceedings of the ACM Symposium on Applied Perception (Los Angeles, California) (SAP '12). ACM, New York, NY, USA, 131-131. https://doi.org/10.1145/2338676. 2338713 